\title{
Evaluation of a Self-Heat Recuperative Thermal Process Based on Thermodynamic Irreversibility and Exergy
}

\author{
Yasuki Kansha ${ }^{1}$, Yui Kotani ${ }^{1}$, Muhammad AzIz ${ }^{2}$, \\ Akira Kishimoto $^{1}$ and Atsushi Tsutsumi ${ }^{1}$ \\ ${ }^{1}$ Collaborative Research Center for Energy Engineering, Institute of Industrial Science, \\ The University of Tokyo, 4-6-1 Komaba, Meguro-ku, Tokyo 153-8505, Japan \\ 2 Advanced Energy Systems for Sustainability, Tokyo Institute of Technology, \\ 2-12-1-I6-25 Ookayama, Meguro-ku, Tokyo 152-8550, Japan
}

\begin{abstract}
Keywords: Thermal Process, Exergy, Energy, Self-Heat Recuperation, Process Design
In this paper, an exergy analysis and a calculation method for a self-heat recuperative thermal process are described. Self-heat recuperation technology has recently been developed and has the characteristics whereby total process heat can be recirculated within the process, leading to a marked reduction in energy consumption. Although this technology can achieve perfect heat circulation in the process, the minimum energy required for the thermal process has not previously been described. According to both the theoretical and graphical analyses in this paper, self-heat recuperative thermal processes can achieve energy requirements close to the energy required for heat transfer from an exergy point of view. In addition, the simple calculation method for the minimum energy required for heat transfer was derived to be fixed as a target value of heat recovery technology. Thus, this technology supports process intensification and is promising for industry to examine the energy saving potential when designing a thermal process.
\end{abstract}

\section{Introduction}

In chemical industries, the physical conditions of process streams must be adjusted to satisfy the operating conditions of the subsequent processes such as separation and reaction processes. In fact, Helmholtz and Gibbs free energies must be less than zero to drive conversion through physical chemistry and thus, these physical conditions must be achieved. These two values can be explained by the second law of thermodynamics (Smith et al., 2005; Atkins and Paula, 2006).

Recently, energy saving technology has attracted increased interest in many countries for suppressing global warming and reducing the use of fossil fuels. However, many conventional energy saving technologies, such as heat recovery technology, are based only on the first law of thermodynamics, energy conservation (Linnhoff et al., 1979; Cerda et al., 1983; Linnhoff and Hindmarsh, 1983; Linnhoff, 1993; Linnhoff and Eastwood, 1997; Ebrahim and Kawari, 2000). Hence, the process design methods based on these technologies are distinguished by heat cascading utilization (Eastop and Croft, 1990; Kemp, 2007).

In contrast, many researchers have paid attention to the analysis of process exergy and irreversibility through consideration of the second law of thermodynamics. However, many of these investigations show only the calculation results of exergy analysis and the possibility for energy

Received on March 8, 2012; accepted on August 16, 2012 DOI: 10.1252 /jcej.12we084

Correspondence concerning this article should be addressed to A. Tsutsumi (E-mail address: a-tsu2mi@iis.u-tokyo.ac.jp). savings of some processes (Lampinen and Heillinen, 1995; Grubbström, 2007), but few of them clearly describe methods for reducing the energy consumption of processes (Chengqin et al., 2002; Som and Datta, 2008).

Recently, Kuchonthara and Tsutsumi $(2003,2006)$ and Kuchonthara et al. (2005) proposed an energy-recuperative, integrated gasification power generation system through exergy analysis and developed design methods for the system. Based on exergy recuperation, Kansha et al. (2009) developed self-heatrecuperation technology, applied it to several chemical processes, and showed the potential energy savings compared with conventional counterparts (Kansha et al. 2010a, 2010b, 2011; Matsuda et al., 2010). This paper presents a simple calculation technique for the minimum energy required for thermal processes that was derived numerically from the point of view of irreversibility and compares between self-heat recuperative thermal processes and conventional processes using simulation to examine the energy saving potential of their processes.

\section{Exergy Losses in Thermal Processes}

A process stream is heated in a thermal process to satisfy the condition of the following process $(\mathrm{X})$, as shown in Figure $1(\mathrm{a}) . T_{\mathrm{i}}$ and $T_{\mathrm{o}}$ are the input and output temperatures of the process stream to the heater, and in particular, $T_{0}$ is the required temperature for the subsequent process (X). Exergy loss in conventional thermal processes such as a fired heater normally occurs during heat transfer between the reaction heat of fuel combustion and the heat of the process stream, as shown in Figure 1(b). This exergy loss mainly is caused by irreversibility during heat transfer. Meanwhile, when no 
heat loss is assumed in this operation, the total reaction heat from fuel combustion transfers to the process stream heat because of the law of energy conservation.

The fuel combustion reaction is assumed to occur at constant temperature $\left(T_{\mathrm{r}}\right)$ and pressure. Therefore, the exergy loss $\left(E X_{\text {h.t.1 }}\right)$ can be derived from the following equation when the process stream is gas and the heat capacity $\left(C_{\mathrm{P}}\right)$ of the stream is independent of temperature during heat transfer in the heater:

$$
E X_{\text {h.t.1 }}=T_{0}\left(\Delta S_{\mathrm{R}}+\Delta S\right)
$$

Here, $\Delta S_{\mathrm{R}}$ has the following relationship with the transferred heat $(Q)$ from fuel combustion reaction to the process stream: $Q=-T_{\mathrm{r}} \Delta S_{\mathrm{R}} ; \Delta S$ is the entropy change of the process stream during heat transfer; and $T_{0}$ is the standard temperature. From this equation, it can be understood that the exergy loss proportionally increases with the difference of $\left|\Delta S_{\mathrm{R}}\right|$ and $|\Delta S|$.

Equation (1) can be derived from the following equations and assumptions. The differential heat $(\mathrm{d} Q)$ is transferred from the hot stream to cold stream without temperature change of both streams during heat transfer. Then, the exergy changes of both streams by heat transfer can be calculated by the following equations with the law of energy conservation.

$$
\begin{aligned}
\mathrm{d} E X_{\text {hot }} & =\mathrm{d} H_{\text {hot }}-T_{0} \mathrm{~d} S_{\text {hot }} \\
& =-\mathrm{d} Q-T_{0} \mathrm{~d} S_{\text {hot }} \\
\mathrm{d} E X_{\text {cold }} & =\mathrm{d} H_{\text {cold }}-T_{0} \mathrm{~d} S_{\text {cold }} \\
& =\mathrm{d} Q-T_{0} \mathrm{~d} S_{\text {cold }}
\end{aligned}
$$

Here, $\mathrm{d} H$ is the enthalpy change and $\mathrm{d} S$ is the entropy change of both streams. Thus, exergy loss $\left(\mathrm{d} E X_{\text {loss }}\right)$ associated with this differential heat $(\mathrm{dQ})$ can be derived as Eq. (4).

$$
\begin{aligned}
\mathrm{d} E X_{\text {loss }} & =-\left(\mathrm{d} E X_{\text {hot }}+\mathrm{d} E X_{\text {cold }}\right) \\
& =T_{0}\left(\mathrm{~d} S_{\text {hot }}+\mathrm{d} S_{\text {cold }}\right)
\end{aligned}
$$

Here, $\mathrm{d} S_{\text {hot }}$ has a negative sign.

Considering the summation of this exergy loss ( $\left.\mathrm{d} E X_{\text {loss }}\right)$, the total exergy loss during heat transfer can be derived as Eq. (1). In addition, Eq. (4) can be rewritten with the temperature difference $(\Delta T)$ between the hot and cold streams, the temperature of cold streams $(T)$, and the relationship of $\mathrm{d} Q=T \mathrm{~d} S_{\text {cold }}=-(T+\Delta T) \mathrm{d} S_{\text {hot }}$ as Eq. (5).

$$
\begin{aligned}
\mathrm{d} E X_{\text {loss }} & =\frac{T_{0}}{T} \Delta T \mathrm{~d} S_{\text {hot }} \\
& =\frac{\Delta T}{T+\Delta T} T_{0} \mathrm{~d} S_{\text {cold }} \\
& =\frac{1}{\left(T / T_{0}\right)+\left(\Delta T / T_{0}\right)} \Delta T \mathrm{~d} S_{\text {cold }}
\end{aligned}
$$

This means that exergy loss of heat transfer is a function of temperature difference between hot and cold streams $(\Delta T)$ and that the exergy loss increases with increasing of $\Delta T$. Figure 1(c) shows a temperature-entropy diagram for this heat transfer. In this figure, $E X_{\text {h.t. }}$ is represented by the proportion of the gray colored area and the area lower than (a)

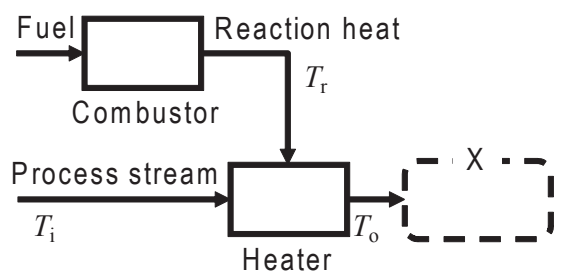

(b)

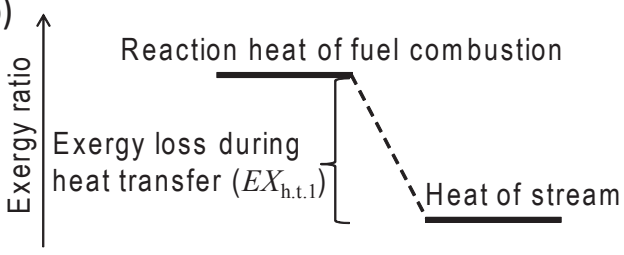

(c)

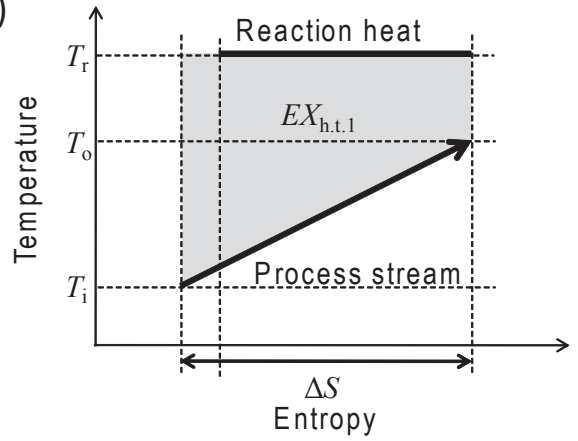

Fig. 1 Conventional thermal process: a) flow diagram; b) exergy ratio; c) temperature-entropy diagram

the composite curve of the process stream represents the amount of heat provided in the heater. In other words, a greater gray colored area represents a larger exergy loss during heat transfer. Thus, to reduce the exergy loss during heat transfer, clearly the gray colored area must be reduced.

In general, a temperature difference $(\Delta T)$ is required for heat transfer, owing to the irreversibility described by the second law of thermodynamics. This causes the exergy loss during heat transfer. Minimization of this exergy loss during heat transfer to the process stream requires a stream (S-a) that provides heat to the process stream, having the same heat capacity as the process stream, and having a temperature that is $\Delta T$ higher than the process stream during heat transfer. Two lines, which represent S-a and the process stream, are plotted in the temperature-entropy diagram in Figure 2. In this figure, these two lines are almost parallel. If the temperature difference $(\Delta T)$ is negligible, the two stream lines coincide and the exergy loss is equal to 0 . In this case, the exergy loss in heat transfer $\left(E X_{\text {h.t. }}\right)$ can be simply expressed by the following equation.

$$
E X_{\text {h.t. } 2} \approx \Delta T \Delta S
$$

This equation can be derived with the following assumptions; $\Delta T$ is much smaller than $T_{0}$ and $T$, and the temperature of the cold stream $(T)$ is close to the standard temperature $\left(T_{0}\right)$. In these assumptions, Eq. (5) means that $\mathrm{d} E X_{\text {loss }}$ becomes close to $\Delta T \mathrm{~d} S_{\text {cold }}$ when $T$ is close to $T_{0}$. Thus, the total exergy loss $\left(E X_{\text {h.t. } 2}\right)$ during heat transfer becomes $\Delta T \Delta S$ due to the summation of this exergy loss $\left(\mathrm{d} E X_{\text {loss }}\right)$. Strictly 
speaking, $E X_{\text {h.t. } 2}$ will be slightly smaller than $\Delta T \Delta S$.

From Figures 1 and 2, it can be seen that $E X_{\text {h.t.2 }}<E X_{\text {h.t.1 }}$. Thus, it can be said that $E X_{\text {h.t. } 2}$ is the theoretical minimum exergy loss for heat transfer and therefore the numerical energy required for heat transfer $\left(W_{\text {numerical }}\right)$ is $\left|E X_{\text {h.t.2 }}\right|$.

On the contrary, if we provide a heat supply stream (S-a), then the exergy loss of heat capacity can be minimized. The most suitable stream for $\mathrm{S}$-a is the process stream itself, but this cannot occur owing to the irreversibility constraint. However, if we add work ( $\left.W_{\text {numerical }}\right)$, then the process stream can theoretically become S-a. Thus, the total heat of the process stream can be circulated internally within the process, so that the energy required for heat transfer is $W_{\text {numerical }}$.

For the design of new energy saving thermal processes, this minimum energy required for heat transfer would be clearly fixed as a target value. Many conventional heat recovery technologies, in which the heat of the process stream is recirculated within the process, have been developed to reduce the energy required for the thermal process. Although a thermal process that employs these technologies can achieve an energy reduction, the exergy loss for heat transfer cannot be reduced to a value as low as $E X_{\text {h.t.2 }}$ represented by Eq. (6), because the total heat cannot be recirculated into the process and an additional heat source is required to provide $\Delta T$. Thus, process designers have paid little attention to this minimum energy required for heat transfer to design a new thermal process. In contrast, a thermal process based on self-heat recuperation technology has been developed, in which the total heat of the process stream is recirculated without heat addition as shown in Figure 3. In this process, energy for compression is needed to drive the internal heat circulation according to the irreversibility when the adiabatic efficiencies of compressor and expanders are 100\%. Note that the numbers beside the composite curves in the temperature-entropy diagram (Figure 3(b)) are the same as stream numbers of the flow diagram (Figure 3(a)). Thus, it can be said that this process is inherently designed by accounting for this minimum exergy loss for heat transfer. Ultimately, the energy required for a thermal process based on self-heat recuperation is equal to $W_{\text {numerical }}\left(=\left|E X_{\text {h.t.2 }}\right|\right)$ when infinite numbers of compressors and heat exchangers are used alternatively and the compressors work adiabatically.

\section{Comparison of Exergy Loss}

Kansha et al. (2009) reported comparisons between the energy required for self-heat recuperative processes and the conventional counterparts. According to the above-mentioned paper, the process simulation was conducted using PRO/II Ver. 8.1 and the entropy difference of each stream was obtained. A comparison between $W_{\text {numerical }}$ for the thermal process calculated from Eq. (6), and the energy required for a conventional thermal process with heat recovery and for self-heat recuperation technology was conducted (cf. Tables 1 and 2). As real fluids, butane was used for the gas stream, and benzene (boiling point $353.2 \mathrm{~K}$ ) was used for

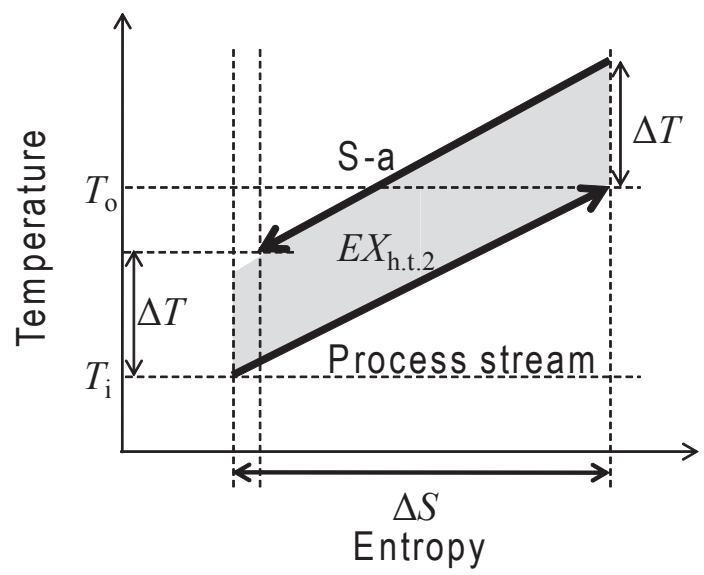

Fig. 2 Temperature-entropy diagram showing the theoretical minimum exergy loss during heat exchange

(a)
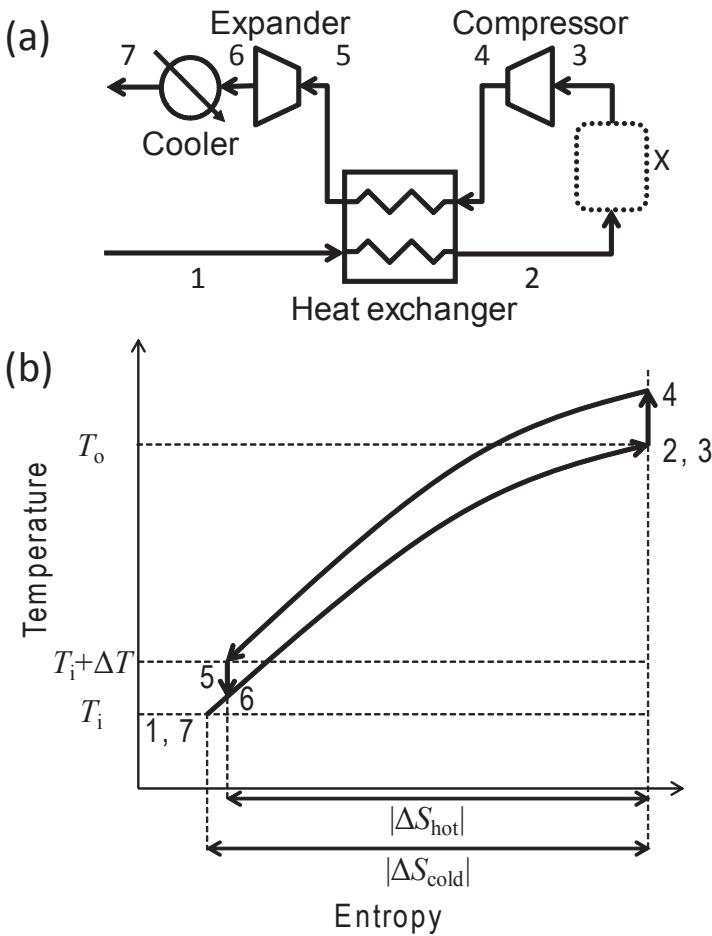

Fig. 3 Self-heat recuperative thermal process in the case of a gas fluid: a) flow diagram; b) temperature-entropy diagram

the vapor/liquid stream. In the calculations for all cases, the streams were heated from $300 \mathrm{~K}$ to a set temperature $T_{1}$, and the flow rate of the stream, $F$, was $100 \mathrm{kmol} / \mathrm{h}$. The SoaveRedlich-Kwong equation of state was used considering the real gas stream. The minimum temperature difference for heat exchange was assumed to be $10 \mathrm{~K}$. The pressure ratio in the compressor was set to maintain a constant temperature increase of $10 \mathrm{~K}$ owing to compression. The efficiency of the heat exchanger was $100 \%$ (i.e. no heat loss), and the adiabatic efficiencies of the compressor and expander were $100 \%$. It can be seen from Tables 1 and 2 that the energy required of the self-heat recuperative thermal process had quite a similar value to the numerical energy required as 


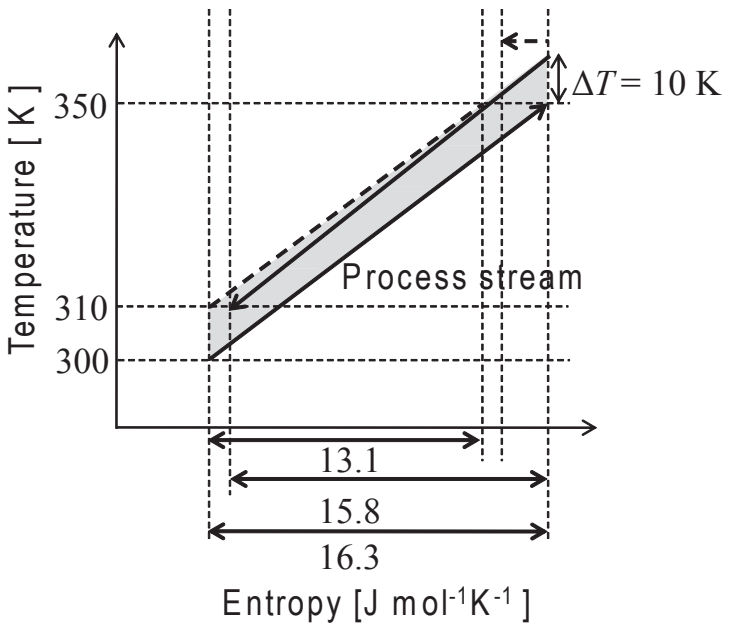

Fig. 4 Temperature-entropy diagram for comparison of energy requirements in the case of butane

calculated with Eq. (6). In addition, the difference between $W_{\text {net }}$ and $W_{\text {numerical }}$ in Table 1 increases with increasing of the temperature $T_{1}$, because the temperature of the process stream becomes further to $T_{0}$, leading to larger error in the numerical energy required. Figure 4 illustrates the temperature-entropy diagram during heat exchange for the case of butane (temperature: $300-350 \mathrm{~K}$ ). In this figure, the solid line represents the composite curves of the hot stream for the self-heat recuperative process and the cold stream, the broken line represents the composite curve of the hot stream for the conventional process with heat recovery, and the gray colored area represents the numerical energy required for heat transfer as calculated with Eq. (6). This figure clearly shows the exergy loss amount as an area surrounded by hot and cold streams. Thus, the energy required for the self-heat recuperative thermal process is much closer to the required numerical energy represented by the gray colored area in Figure 4 than that of the conventional thermal process with heat recovery. In the same way, Figure 5 illustrates the

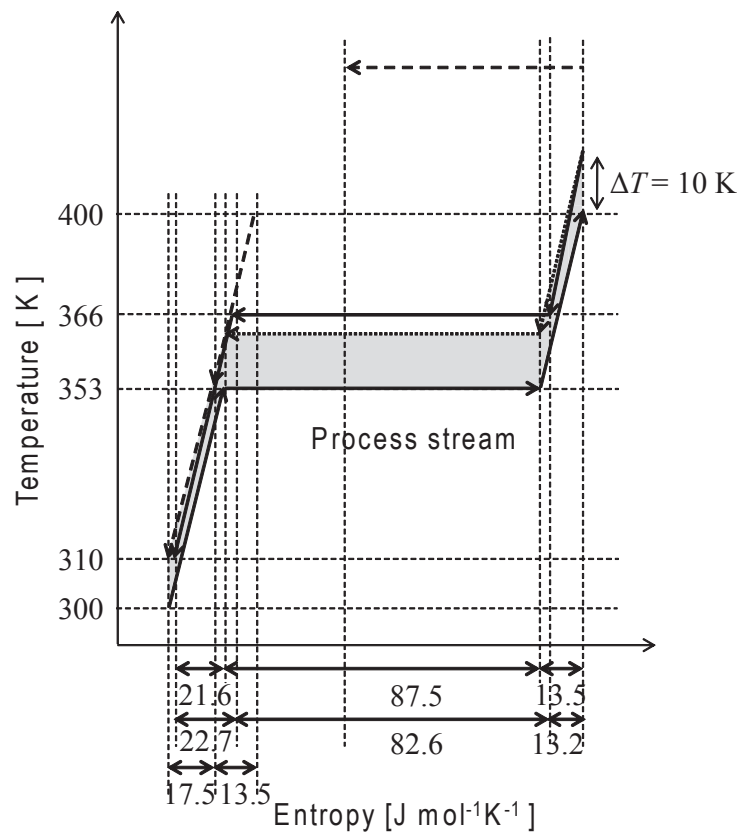

Fig. 5 Temperature-entropy diagram for comparison of energy requirements in the case of benzene

exergy amounts in the cases of benzene. Note that the solid line represents the composite curves of the hot stream for the self-heat recuperative process and the cold stream, the broken line represents the composite curve of the hot stream of a conventional process with heat recovery, and the gray colored area represents the numerical energy required for heat transfer as calculated with Eq. (6). To calculate the energy required in these two cases, we obtain the difference in entropy $\left(\Delta S_{\text {trs }}\right)$ during phase transition (vaporization) using Eq. (7).

$$
\Delta S_{\text {trs }}=\frac{\Delta H_{\text {trs }}}{T_{\mathrm{b}}}
$$

Here, $\Delta H_{\text {trs }}$ is the difference in enthalpy during phase transi-

Table 1 Comparison of energy requirements for the case of butane

\begin{tabular}{cccccccc}
\hline \multicolumn{9}{c}{ Self-heat recuperation } & & Heat recovery & $\begin{array}{c}\text { Numerical en- } \\
\text { ergy required }\end{array}$ \\
\hline$T_{1}[\mathrm{~K}]$ & $W_{\mathrm{C}}[\mathrm{kW}]$ & $W_{\mathrm{E}}[\mathrm{kW}]$ & $W_{\text {net }}[\mathrm{kW}]^{*}$ & $Q_{\mathrm{Hx}}[\mathrm{kW}]$ & $Q_{\mathrm{FH}}[\mathrm{kW}]$ & $Q_{\mathrm{Hx}}[\mathrm{kW}]$ & $W_{\text {numerical }}[\mathrm{kW}]$ \\
\hline 350 & 30.0 & 25.6 & 4.4 & 147.7 & 31.0 & 116.7 & 4.5 \\
400 & 34.0 & 25.4 & 8.6 & 313.7 & 34.6 & 279.1 & 8.9 \\
450 & 37.5 & 25.0 & 12.5 & 497.0 & 38.0 & 459.0 & 13.2 \\
\hline
\end{tabular}

$* W_{\text {net }}=W_{\mathrm{C}}-W_{\mathrm{E}}$; fluid, butane $100 \mathrm{kmol} / \mathrm{h}$

Table 2 Comparison of energy requirements for the case of benzene

\begin{tabular}{cccccc}
\hline & \multicolumn{2}{c}{ Self-heat recuperation } & & Heat recovery & \multicolumn{2}{c}{$\begin{array}{c}\text { Numerical energy } \\
\text { required }\end{array}$} \\
\hline$T_{1}[\mathrm{~K}]$ & $W_{\text {net }}[\mathrm{kW}]^{*}$ & $Q_{\mathrm{HX}}[\mathrm{kW}]$ & $Q_{\mathrm{FH}}[\mathrm{kW}]$ & $Q_{\mathrm{HX}}[\mathrm{kW}]$ & $W_{\text {numerical }}[\mathrm{kW}]$ \\
\hline 400 & 34.93 & 1195.4 & 897.3 & 298.1 & 34.1 \\
\hline
\end{tabular}

$* W_{\text {net }}=W_{\text {C }}$ fluid, benzene $100 \mathrm{kmol} / \mathrm{h}$ 
tion and $T_{\mathrm{b}}$ is the boiling temperature.

\section{Conclusion}

In this paper, the energy requirements of recently developed self-heat recuperative thermal processes were examined and compared with the theoretical energy required for a thermal process, calculated from the exergy loss for heat transfer both numerically and graphically. In addition, in the course of comparison, the simple equation of the numerical minimum energy required for heat transfer has been derived. This equation is not only simple but also indicates the amount of the energy required visually in the graph. As a result, it provides the useful information of the energy savings for the thermal process without any complex process simulations. Through these comparisons, we can quantify the energy saving potential of thermal processes and conclude that self-heat recuperative thermal processes have great potential for energy savings in industry.

\section{Nomenclature}

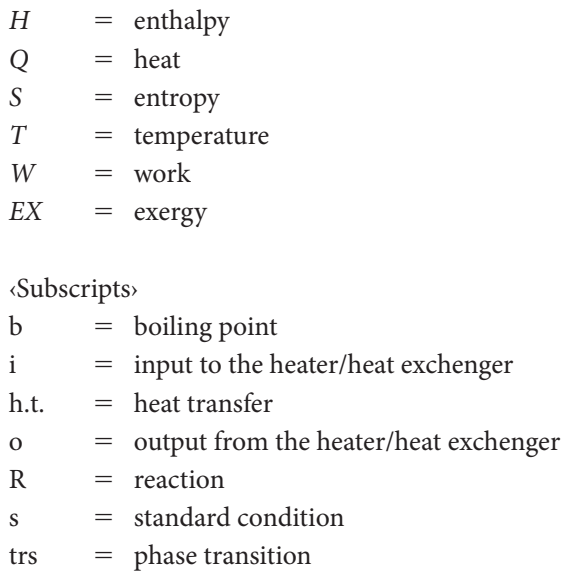

\section{Literature Cited}

Atkins, P. and J. de Paula; Atkins' Physical Chemistry, 8th ed., pp. 76-116, Oxford University Press, New York, U.S.A. (2006)

Cerda, J., A. W. Westerberg, D. Mason and B. Linnhoff; "Minimum Utility Usage in Heat Exchanger Network Synthesis," Chem. Eng. Sci., 38, 371-387 (1983)

Chengqin, R., L. Nianping and T. Guangfa; "Principle of Exergy Analysis in HVAC and Evaluation of Evaporative Cooling Schemes," Build. Environ., 37, 1045-1055 (2002)

Eastop, T. D. and D. R. Croft; Energy Efficiency for Engineers and Technologists, pp. 203-246, Longman Scientific \& Technical, London, U.K. (1990)
Ebrahim, M. and A. Kawari; "Pinch Technology: An Efficient Tool for Chemical-Plant and Capital-Cost Saving," Appl. Energy, 65, 45-49 (2000)

Grubbström, R. W.; "An Attempt to Introduce Dynamics into Generalized Exergy Consideration," Appl. Energy, 84, 701-718 (2007)

Kansha, Y., N. Tsuru, K. Sato, C. Fushimi and A. Tsutsumi; "Self-Heat Recuperation Technology for Energy Saving in Chemical Processes," Ind. Eng. Chem. Res., 48, 7682-7686 (2009)

Kansha, Y., N. Tsuru, C. Fushimi, K. Shimogawara and A. Tsutsumi; "An Innovative Modularity of Heat Circulation for Fractional Distillation," Chem. Eng. Sci., 65, 330-334 (2010a)

Kansha, Y., N. Tsuru, C. Fushimi and A. Tsutsumi; "Integrated Process Module for Distillation Processes Based on Self-Heat Recuperation Technology," J. Chem. Eng. Japan, 43, 502-507 (2010b)

Kansha, Y., A. Kishimoto, T. Nakagawa and A. Tsutsumi; "A Novel Cryogenic Air Separation Process based on Self-Heat Recuperation," Sep. Purif. Technol., 77, 389-396 (2011)

Kemp, I. C.; Pinch Analysis and Process Integration: A User Guide on Process Integration for the Efficient Use of Energy, 2nd ed., pp. 15-40, Butterworth-Heinemann, Elsevier, Burlington, U.S.A. (2007)

Kuchonthara, P. and A. Tsutsumi; "Energy-Recuperative Biomass Integrated Gasification Power Generation System," J. Chem. Eng. Japan, 36, 846-851 (2003)

Kuchonthara, P., S. Bhattacharya and A. Tsutsumi; "Combination of Thermochemical Recuperative Coal Gasification Cycle and Fuel Cell for Power Generation,” Fuel, 84, 1019-1021 (2005)

Kuchonthara, P. and A. Tsutsumi; "Energy-Recuperative Coal-Integrated Gasification/Gas Turbine Power Generation System," J. Chem. Eng. Japan, 39, 545-552 (2006)

Lampinen, M. J. and M. A. Heillinen; "Exergy Analysis for Stationary Flow Systems with Several Heat Exchange Temperatures," Int. J. Energy Res., 19, 407-418 (1995)

Linnhoff, B., D. R. Mason and I. Wardle; "Understanding Heat Exchanger Networks," Comput. Chem. Eng., 3, 295-302 (1979)

Linnhoff, B. and E. Hindmarsh; "The Pinch Design Method for Heat Exchanger Networks," Chem. Eng. Sci., 38, 745-763 (1983)

Linnhoff, B.; "Pinch Analysis-A State-of-the-Art Overview," Chem. Eng. Res. Des., 71, 503-522 (1993)

Linnhoff, B. and A. R. Eastwood; "Overall Site Optimization by Pinch Technology," Chem. Eng. Res. Des., 75, S138-S144 (1997)

Matsuda, K., K. Kawazuishi, Y. Hirochi, R. Sato, Y. Kansha, C. Fushimi, Y. Shikatani, H. Kunikiyo and A. Tsutsumi; "Advanced Energy Saving in the Reaction Section of Hydro-Desulfurization Process with Self-Heat Recuperation Technology," Appl. Therm. Eng., 30, 2300-2306 (2010)

Smith, J. M., H. C. Van Ness and M. M. Abbott; Introduction to Chemical Engineering Thermodynamics, 7th ed., pp. 159-198, McGawHill, New York, U.S.A. (2005)

Som, S. K. and A. Datta; "Thermodynamic Irreversibilities and Exergy Balance in Combustion Processes," Prog. Energy Combust. Sci., 34, 351-376 (2008) 